\title{
PERINEOLOGY: A NEW AREA
}

\author{
J. BECO1, J. MOUCHEL 2 \\ 1 GROUPEMENT EUROPÉEN DE PÉRINÉOLOGIE AND LIĖGE UNIVERSITY, \\ CHU SART-TILMAN, DEPARTMENT OF GYNECOLOGY, BELGIUM \\ 2 GROUPEMENT EUROPÉEN DE PÉRINÉOLOGIE AND CLINIQUE DU TERTRE ROUGE, \\ LE MANS, FRANCE
}

Keywords: Perineology, urinary incontinence, anal incontinence, prolapse, constipation, sexual troubles, dysuria, holistic

SUMMARY: Perineology is the result of the merging between urogynecology and coloproctology. This "three-axis approach" is now becoming widely accepted but Perineology is more than a "three axis approach" of the perineum...

Perineology deals only with the perineum functional troubles (including pains). Organic diseases (cancer, stones, polyps,...) at any of the three levels must be treated as usual by urologist, gynecologist or coloproctologist.

This approach has to be interdisciplinary and not multidisciplinary. There is only one boss who is the "architect of the perineum", somebody who knows a lot about the anatomy and the physiology of the three axis. This new specialist is called "perineologist". This person could be the surgeon or somebody who tells the surgeon what to do. The perineologist should have a holistic view (integration of the psychology, the way of life, the abdominal wall muscles... in the approach) of the women and should respect the limits of the concept.

The aim of Perineology is to restorate "ad integrum" the anatomy in the respect of biomechanics and physiology. Ideally, each defect must be corrected without inducing troubles on the other levels (primum non nocere). The benefit - risk ratio has to be evaluated for each of the procedures. In surgery, seven key procedures are proposed to obtain such a result (defect specific, efficient and low risk) in the majority of the cases.

The functional state of the perineum can be summarized by a T.A.P.E. (Three Axis Perineal Evaluation diagram):

- gynecological axis $=$ sexual troubles - prolapse

- urological axis = urinary incontinence-dysuria

- coloproctological axis = constipation - fecal incontinence.

The normal shape of the T.A.P.E is hexagonal. It is a good tool to introduce all the practitioner of this area in a more holistic approach of the woman. It is based on the history of the patient not on the clinical examination. 


\section{PERINEOLOGY:}

\section{FROM A NAME TO A CONCEPT}

The name "Perineology " is a neologism which means the study of the perineum. It has been used for the first time in Italy by G. Dodi in 1990 (1).

But Perineology is far more than just a new name, it is a real new concept.

The landmarks of this concept could be summarized in four points:

1. Perineology is only dealing with the functional troubles of the three axis of the perineum. Each organic problem should be treated by its specialist. For example, a bladder stone must be treated by the urologist; a uterine fibrome by the gynecologist and an anal cancer by the colo-proctologist surgeon.

2. Perineology is a holistic approach of the woman including the abdominal wall, the psychology, the spinal cord, the behavior ... We want to help a woman not to treat an isolated perineum. For example, think about constipation induced by sexual abuse before operating a rectocele.

3. The aim of Perineology is to promote efficient "defect specific" treatments where the surgeon tries to recreate the anatomy "ad integrum" together with avoiding side effects on any of the three axis and at the lowest risk for the patient (primum non nocere). "Should Burch colposuspension still be performed?" (2) was, for the urogynecologist, a paper which emphasized the detrimental role of this worldwide used operation on the anorectal axis (constipation, rectocele, enterocele and even anal incontinence can occur after a Burch). Other usual procedures are also on the "black list" like anterior levator myoraphy in the treatment of rectocele which increases dyschesia and create dyspareunia (3, 4, 5,6).

4. Perineology is an interdisciplinary approach. To put together all the specialists of the perineum around the woman is already a relevant idea but in this multidisciplinary approach each of the participants only thinks about his own area and nobody has a global vision. The female perineum needs its own specialist (only one boss !), the "Perineologist", who will be a real architect always thinking at the three axis before defining a restoration strategy $(7,8,9,10,11)$. Of course this specialist has to respect the landmarks of the concept.

\section{HOW COULD WE INTRODUCE PERINEOLOGY IN THE PRACTICE ?}

The first step would be speaking the same language. For example, a urologist has to understand what is a descending perineum syndrome, a coloproctologist what is the "hammock hypothesis", a gynecologist what is the pudendal nerve and so on.

The second step would be really learning the "three axis approach". This approach begins with the history of the patient. To increase the interest of every surgeon for the perineological management of the perineum we have created a diagram, the "T.A.P.E." (Three $\underline{\text { Axis }}$ Perineal Evaluation) ( $11,12,13)$, designed to summarize the functional state of an individual's perineum (subjective approach). Under normal circumstances, 
it is hexagonally shaped (Figure 1). It takes into account the 6 standard perineal disorders presented in 3 axis with an excess and a failure end for each :

- the gynaecological axis:

excess end $=$ dyspareunia

failure end $=$ prolapse

- the urological axis:

excess end $=$ dysuria

failure end $=$ urinary incontinence

- the colo-proctological axis:

excess end $=$ dyschesia

failure end $=$ anal incontinence

Of course the TAPE is just the beginning of the work. Each future "Perineologist" has to learn how to make a complete history of the patient, how to realize a relevant perineal examination of the three axis and how to confirm the diagnosis.

The third step would be designing the best restoration project. If surgery is the only solution for the patient, the Perineologist has to decide how to operate her. We think that with only 7 basic procedures it is possible to manage the great majority of the functional troubles of the perineum (Figure 2). These gestures are of course in agreement with the concept of Perineology and only the disturbed anatomical structures should be treated. We are going to validate this approach.

Figure 1 - Normal TAPE (Three $\underline{\text { Axis }}$ Perineal Evaluation). This patient has no functional perineal trouble (quotation " $O$ " at the end of the 3 axis).

\section{Three Axis Perineal Evaluation}

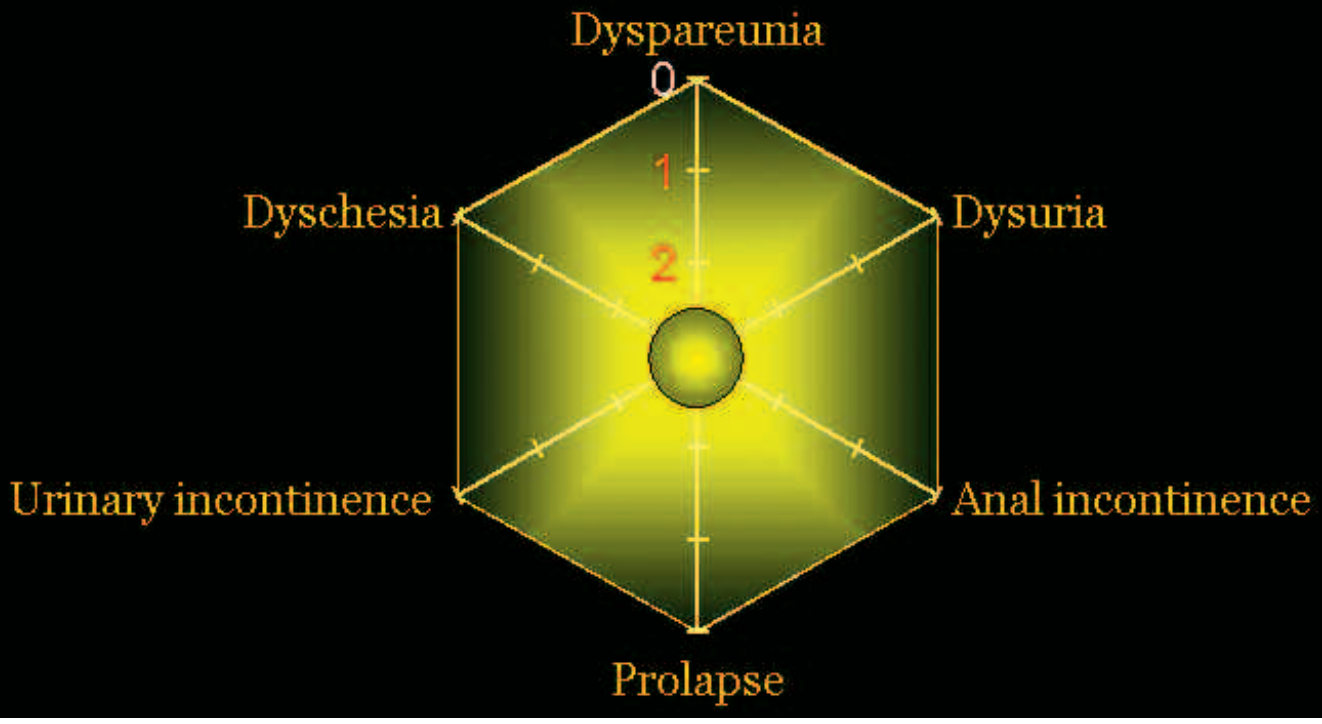


Figure 2 - The 7 basic surgical procedures in Perineology (our approach).

These procedures are of course in agreement with the concept of Perineology and only the disturbed anatomical structures should be treated.

MVT = mini vaginal tape according to Mouchel (2).

TVT $=$ tension free vaginal tape (or similar procedures)

Opening of the Retzius space must be avoid (2).

Vaginal lifting $=$ removal of the excess of vaginal skin.

Fascia $=$ restoration of the fascia with or without mesh (myoraphy of the "levator ani", puborectalis or levator plate, between the vagina and the ano-rectum must be avoid (3)(4))

Avoid rectopexia, promonto-fixation and sacro-spinal fixation.

More specific surgical procedures could be used for specific indications (artificial urinary or anal sphincter, neuromodulation...)

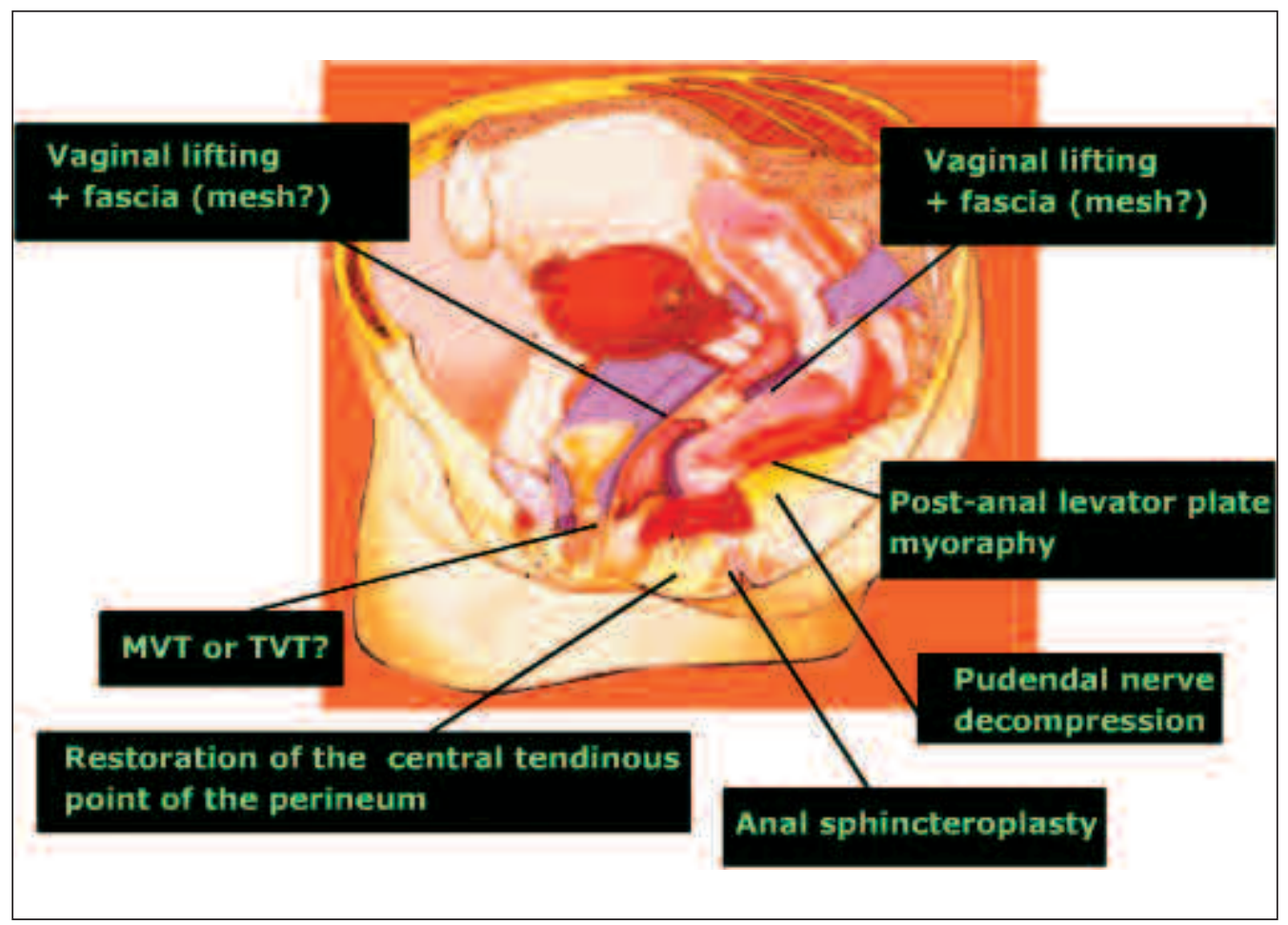

\section{PRACTICAL EXAMPLES OF PERINEOLOGY}

Case number 1: Mrs C.D., 40 years of age, was suffering from genuine urinary stress incontinence (GSI), which resisted classical reeducation. Urody- namics confirmed the existence of standard GSI. The urogynecological approach led to the performance of a Burch anterior colposuspension. Following the procedure, the shape of the TAPE (Figure 3) indicated to what point the perineological outcome was 
Figure 3 - Example of a T.A.P.E. after a classical anterior colposuspension (Burch) if the surgeon only wants to treat the urinary incontinence (mono axis view). After this very thigh colposuspension, urinary incontinence is cured (incontinence quotation " $O$ ") but with a severe dysuria (dysuria quotation " 2 "). The rectocele has increased (prolapse quotation " 2 ") inducing a very severe dyschesia (dyschesia quotation " $2 ")$.

\section{Three Axis Perineal Evaluation}

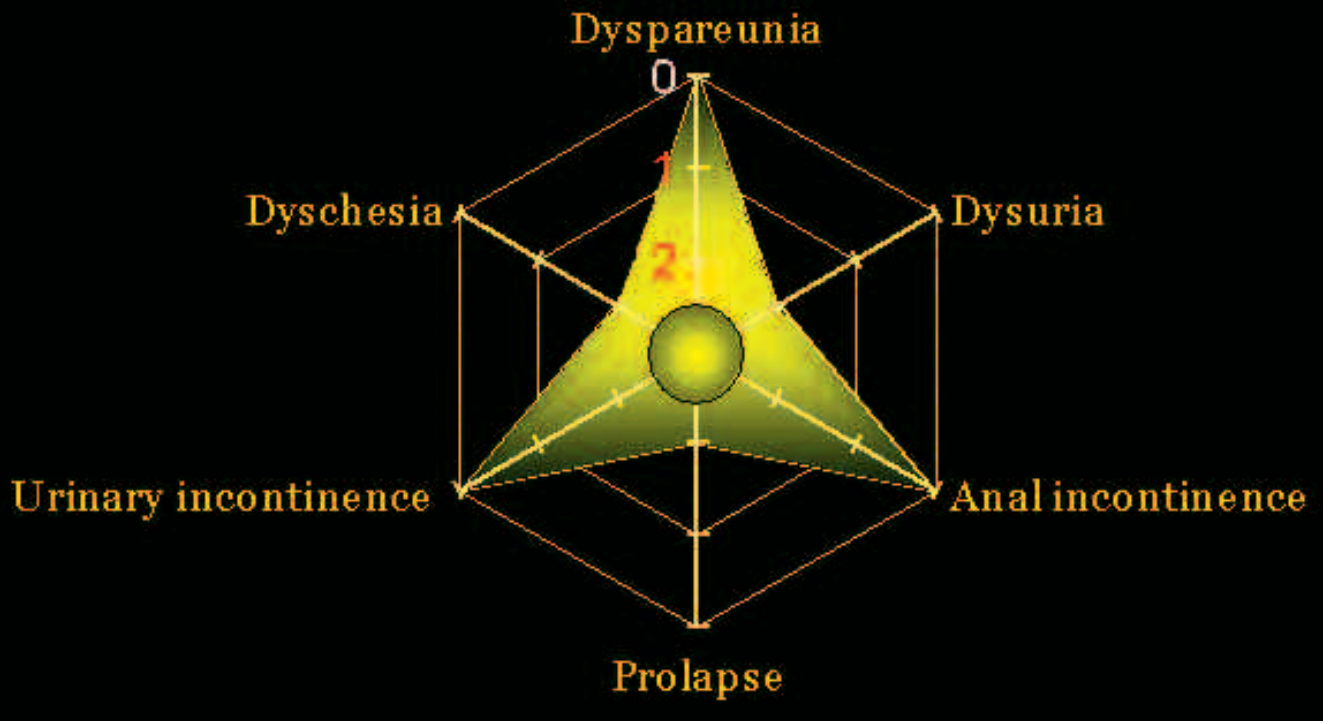

mediocre in this patient cured of her GSI. Why was this the case ? The preoperative TAPE (Figure 4) showed the existence of a rectocele responsible for initial stage dyschesia. The traction towards the front of the vagina cured the GSI; the Urogynecologist was happy!

But the rectocele and the dyschesia became worse. The Perineologist was furious ! In a case like this, we would have preferred sub-urethral support without tension and a posterior vaginal lifting with restoration of the Denonvil- liers fascia (without anterior miorraphy of the levators which might make the dyschesia worse).

Case number 2: Mrs A.W., 65 years old, was suffering from debilitating " urge incontinence ". The urogynecological examination concluded there was bladder instability. The latter was treated with an anticholinergic drug that improved the urinary incontinence. The urogynecologist was happy! 
Figure 4 - T.A.P.E. before the Burch in the same patient. She has a severe genuine stress urinary incontinence (incontinence quotation " 2 "). The patient has also a rectocele inducing mild trouble by itself (prolapse quotation " 1 ") but with dyschesia (dyschesia quotation " $1 "$ ).

\section{Three Axis Perineal Evaluation}

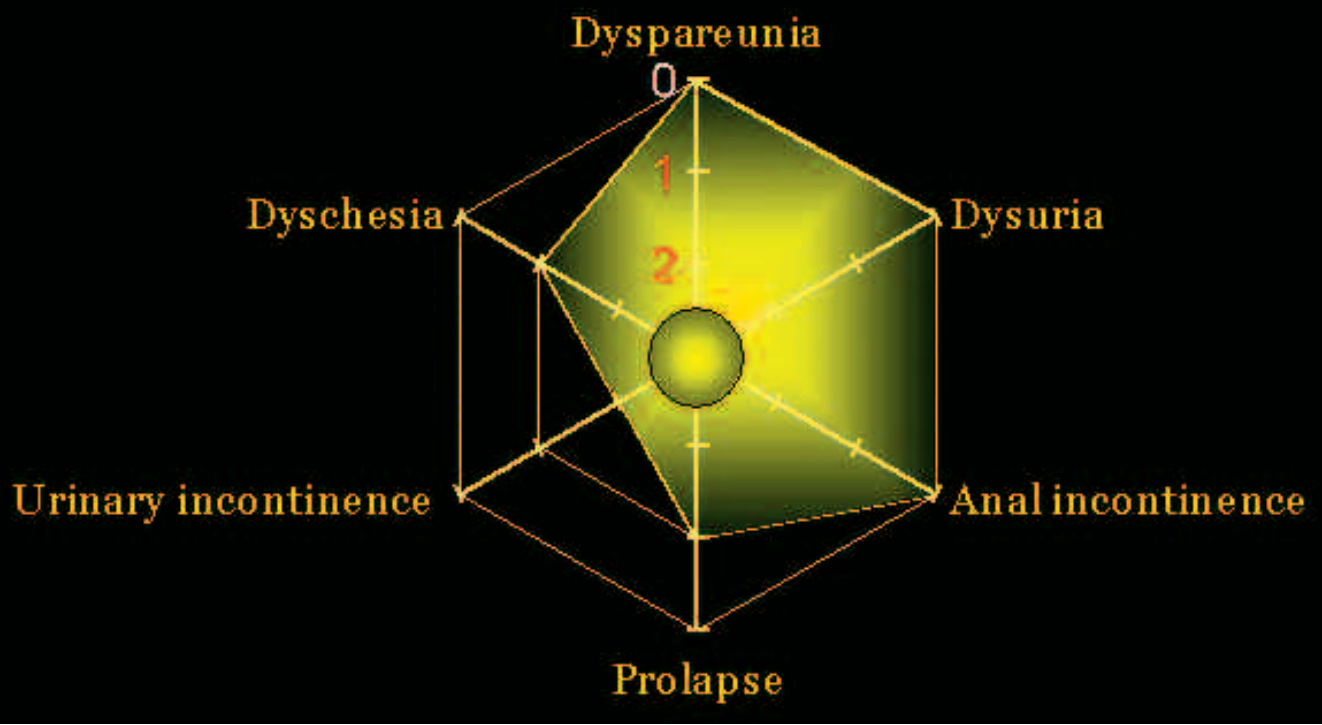

But was it really logical? Not really, since Mrs. A.W a also presented with dyschesia and a major descending perineum syndrome. The use of an anticholinergic agent would worsen her constipation and thus her perineal descent. The increase in the latter would lead to a progressive stretching of the pudendal nerves, and over time, to fecal incontinence!

\section{CONCLUSION}

The aim of Perineology is to understand the equilibrium of the perineum and to preserve or restore it. Perineology, an independent specialty in its own right, subsequently appears as the logical and indisputable successor to urogynecology and colo-proctology in the management of the functional problems of the female perineum. 


\section{REFERENCES}

$1-$ G. DODI :

Perineologia: un neologismo?

Rivista Italiana di Colon-Proctologia, p. 113, Vol. 9, 1990. Atti del Symposio Internazionale di Perineologia , Venezia, 9 novembre 1990.

2 - J. BECO, J. MOUCHEL :

Faut-il encore faire des Burch?

J. Gynecol. Obstet. Biol. Reprod., 1995, 24, 772-774.

3 -A. SHAFIK :

A new concept of the anatomy of the anal sphincter mechanism and the physiology of defaecation. XXVIII-Complete rectal prolapse: a technique repair. Colo-prortology 1987, 6, 345-352.

4 - KAHN M.A., STANTON S.L. :

Posterior colporraphy: its effect on bowel and sexual function.

Br. J. Obstet. Gynaecol., 1997, 104, 82-86.

5 -Eds. J. BECO, J. MOUCHEL et G. NELISSEN :

La Périneologie... comprendre un équilibre et le préserver.

Maison d'édition Odyssée 1372 (1999), Verviers, Belgique.

6 -ROBINSON D., WADSWORTH S., CARDOZO L., BIDMEAD J., RUFFORD J. : Fascial posterior vaginal repair leads to increased sexual satisfaction.

Int. Urogynecology Journal, 2001, 12, Suppl. 3, Abstract 154.

7 -J. BECO :

The gynecologist "perineologist" or how to restore normal function in the three levels of the perineum.

Symposium of urogynecologia. Skopje, Republic of Macedonia, 17-19 nov.

1996.

8 -J. BECO, G. DE BISSCHOP, R. DIJKSTRA, G. NELISSEN, J. MOUCHEL. :

La Périnéologie : comprendre un équilibre et le préserver...

J. Gynecol. Obstet. Biol. Reprod., 1999 Dec, 28(8) : 855-6.

9 -J. MOUCHEL :

From Urogynecology to Perineology.

XVI FIGO World Congress, Washington, USA, September 3-8, 2000.

Abstract SS4.04.01 
10 - BECO J., DE BISSCHOP G., DIJKSTRA R., NELISSEN G., MOUCHEL J. : La périnéologie....comprendre un équilibre et le préserver J Gynecol Obstet Biol Reprod (Paris). 1999 Dec;28(8):855-6.

11 - BECO J., MOUCHEL J. :

Editorial: Understanding the concept of perineology.

Int Urogynecol J Pelvic Floor Dysfunct. 2002;13(5):275-7

12 - J. BECO :

Perineology : definition and principles

XVI FIGO World Congress, Washington, USA, September 3-8, 2000.

Abstract SS4.04.02.

13 - J. BECO :

Perineology: a new name, a new concept, a new specialty, a new tool (the T.A.P.E.)

3rd International Congress on Pelvic Floor Disorders

Cairo, Egypt, March 14-17, 2001. 